\title{
La titularidad pública de la praeda bellica durante la República romana
}

José Miguel Piquer-Maríl

\section{RESUMEN}

En el contexto de los estudios de derecho público y, en particular, del patrimonio del Estado, el presente artículo examina la formación de construcciones acerca de los bienes públicos, en especial, acerca de la praeda bellica como bien que pertenece al pueblo romano durante la época de la República. Se trata de un estudio de la institución y de su titularidad, a través del cual se busca ahondar en la comprensión de las relaciones jurídico-patrimoniales que determinan la existencia de esta rama del derecho.

Palabras clave: Praeda bellica, populus Romanus, Derecho público, Titularidad pública, República romana.

\section{State Ownership of the praeda bellica during the Roman Republic}

\section{ABSTRACT}

From a Public Law perspective, and with particular regards to the subject of public property, this paper examines the praeda bellica as an asset belonging to the Roman people during the times of the Republic. Through an analysis

1 Doctor en Derecho por la Universidad Jaume I de Castellón, Castellón, España, y profesor de Derecho Romano de la Universitat de València Estudi General, Valencia, España. Correo-e: jomipima@uv.es Fecha de recepción: 10 de noviembre de 2016. Fecha de modificación: 10 de diciembre de 2016. Fecha de aceptación: 14 de diciembre de 2016. Para citar el artículo: Piquer-Marí, J. M., "La titularidad pública de la praeda bellica durante la República romana", Revista digital de Derecho Administrativo, n. ${ }^{\circ} 17$, primer semestre, Universidad Externado de Colombia, 2017, pp. 163-189. DOI: http://dx.doi.org/10.18601/21452946. n17.10 
of the ownership of the praeda bellica, the research intends to provide an in depth understanding of legal and proprietary relationships shaping the Public branch of the Law.

Keywords: Praeda bellica, populus Romanus, Public Law, Public Property, Roman Republic.

\section{INTRODUCCIÓN}

La investigación en el campo del derecho público romano, especialmente en España, se ha desarrollado gracias al impulso del Prof. Antonio Fernández De Buján ${ }^{2}$ y su escuela; este esfuerzo ha fructificado en toda una línea de investigación que se plasma en publicaciones y jornadas de relevancia científica en España y el extranjero. Hemos tenido el honor de contribuir humildemente a esa labor en las recientes Jornadas de Derecho Administrativo y Fiscal Romano que se llevaron a cabo en Turín en mayo de 2015, así como de colaborar con la Revista digital de Derecho Administrativo de la Universidad Externado de Colombia. Producto de las Jornadas en mención fue un trabajo que tuvo por objeto la titularidad del botín de guerra, la praeda $a^{3}$ bellica, como patrimonio romano y del cual pensamos en la posibilidad de completar su examen, profundizando

2 Podemos destacar algunas de sus obras como son: Derecho público romano, Madrid, 19. ed., 2016, que se renueva año tras año ${ }_{i}$ "Perspectivas de estudio en temática de derecho administrativo romano surgidas a tenor del pensamiento y de la obra de Giambattista Impallomeni", Index, vol. 26, 1998, pp. 463-487. Del mismo, Derecho público romano, Pamplona, 12. ${ }^{a}$ ed., 2009, e "Instituciones, hechos y actividad de orden administrativo en la experiencia jurídica romana en derecho administrativo histórico", en Xornadas e Seminarios. Escola Galega de Administración Pública, pp. 119-157. En su fecundo magisterio, es también director de la Sección de "Derecho Administrativo y Fiscal Romano" de la Colección de Monografías de Derecho Romano de la Editorial Dykinson, que supera la veintena de monografías elaboradas por los principales investigadores doctores en derecho romano versados en la materia, a las que nos remitimos para la profundización en lo concerniente a los ámbitos de la experiencia administrativa romana. Este investigador ha destacado, entre otras razones, por su trabajo en el estudio del arbitraje, como se puede comprobar en multitud de obras dedicadas al tema como: "El arbitraje de derecho público en la experiencia jurídica romana", en El Cronista del Estado Social y Democrático de Derecho, 37, 2013, pp. 48-61, y "Conflicto, controversia, contraposición, contienda, polémica, oposición: proceso y litigio", en Ensayos de bumanidades, 6, 2012, pp. 61-64.

3 Nos vemos impelidos a realizar una precisión en nota a pie de página. Cuando utilizamos el término "botín" en este trabajo, lo hacemos para referirnos, en todo momento, a praeda, diferenciándola de otros términos como manubiae y spolia. En el contexto militar, entendemos por praeda lo que se obtiene por la fuerza de las armas, sea en una guerra exterior, sea en una guerra civil. Este sentido genérico lo recogen tanto las fuentes literarias (Plauto: Auorti praedam ab hostibus nostrum salute socium, CATÓN, Orat. 50: Nunquam ego praedam neque quod ab hostibus captum esset neque manubias inter pauculos amicos meos divisi; Varrón: praeda est ab bostibus capta ${ }_{\text {; }}$ Cicerón: quibus ex hostium spoliis, de qua victoria, qua ex praeda aut manubiis baec abs te donatio constituta est?; Servio: praeda est quae eripitur, praemium quod offertur e Isidoro de Sevilla: Spolia 
en su fundamentación y ampliando la perspectiva cronológica para, de este modo, obtener un estudio sobre la configuración jurídica de la titularidad del botín de guerra como patrimonio del pueblo romano (patrimonio del Estado) durante la República.

Esta problemática surge al poner en duda la tradicional perspectiva privatística sobre la adquisición por occupatio de la praeda bellica que niega que el "Estado" adquiera directamente el botín tras la victoria militar. Esta tesis se ha sostenido especialmente en los testimonios clásicos de Gayo y Celso recogidos en D. 41.1.5.1 y $7^{[4]}$. Fue Bona ${ }^{5}$ quien, con mayor profundidad ${ }^{6}$, puso en evidencia la necesidad de revisar la tesis privatística sobre el título de adquisición del botín al considerar que este formaba parte directamente de los derechos quae sunt propria civitatis atque imperii ${ }^{7}$, acentuando con ello la perspectiva iuspublicística.

Tanto los argumentos privatísticos, sólidamente fundados en la literalidad de los textos de los juristas romanos, como publicísticos, que encuentran el apoyo en las fuentes literarias, han intentado ser aunados acudiendo a argumentos situacionales que explicarían un régimen u otro ${ }^{8}$, por ejemplo, respecto a las cosas de los enemigos en tiempo de guerra que se encuentran en territorio romano; cosas que tienen los extranjeros pertenecientes a un Estado no amigo

bostium: praeda, manubiae, exuviae, partes), como las jurídicas (D. 49.15.28: si quid bello captum est, in praeda est, non postliminio redit).

4 Especialmente D. 41.1.5.7: Item quae ex bostibus capiuntur, iure gentium statim capientium fiunt; y D. 41.1.51.1: Et quae res bostiles apud nos sunt, non publicae, sed occupantium fiunt. En parte, sigue esta doctrina KaRL-HeInZ VogeL, "Zur rechtlichen Behandlung der römischen Kriegsgewinne”, Zeitschrift Savigny Stitfung, vol. 66, 1948, pp. 394-422. Pierangelo Catalano, Populus Romanus Quirites, Torino: Giappichelli,1975, pp. 142 ss.

5 Ferdiando Bona. "Osservazioni sull'acquisto delle 'res bostium' a seguito di 'direptio"', en Studia et documenta bistoriae iuris, vol. 24, 1958, pp. 238-268; "Praeda di guerra e occupazione privata di 'res hostium"', en Studia et documenta bistoriae iuris, vol. 25, 1959, pp. 309-370, en especial 310, Rosanna OrTu. "La guerra tra economia e diritto nella antica Roma", en Diritto@Storia, vol. 4, 2005.

6 Antes, según cita Bona, Praeda, p. 312, n. 10, autores como E. Costa E., Storia del diritto privato, 2. ${ }^{a}$ ed., Torino, 1925, p. 213, o RUDOLPH VON IHERING, Vorgeschichte der Indoeuropäer, Leipzig: Breitkopf und Härtel-Duncker und Humblot, 1894, pp. 398 ss., ya habían mantenido el carácter público del botín.

7 Cic., De Orat. 1.46.201; Brut. 269; orat. domo, 33; pro Balbo 34; de legibus 1.4.14. D. 50.16.15. Antonio FernándeZ de Buján, Derecho público, p. 251. Ulp. D.1.1.1.2, quien define de forma dogmática que es ius publicum y asocia su existencia a la necesidad de regular aquello que es de utilidad pública, lo que nos debe llevar a considerar, si aceptamos de forma intemporal la definición de Ulpiano, que el botín es publice utilitatis; Hans AnKum, "La noción de ius publicum en derecho romano", Anuario de Historia del Derecho Español, vol. 53, 1983; ANSELMO ArICÓ, "Ius publicum-ius privatum in Ulpiano, Gaio e Cicerone", AUPA 37, 1983, pp. 447 ss.; del mismo autor, "Partes iuris", Annali della Università di Palermo, vol. 39, 1987; MAX KASER, "Ius publicum und ius privatum", Zeitscbrift Savigny Stitfung, vol. 103, 1986, 1 ss.; Guglelmo NocerA, "Privato e pubblico", ED, vol. 35, 1986; Jean GaUdemet, "Utilitas publica", Revue bistorique du droit français et etranger, vol. 29, 1951, pp. 465 ss.; CARLO LONGO, "Utilitas publica", Labeo, vol. 18,1972, pp. 7-71.

8 Bona, Praeda, pp. 311-312, con bibliografía. 
de Roma en tiempo de paz, o el caso del saqueo; de tal forma que los bienes capturados pertenezcan, en parte al "Estado", en parte a los soldados.

Pese a las cuestiones que se pueden suscitar en torno a la discusión de naturaleza iusprivatística o a su interrelación con la tesis iuspublicista, nuestro estudio no tiene por finalidad negar la validez de la tesis de la occupatio ni tampoco intentar conjugar ambas tesis, sino ahondar un poco más en la teoría iuspublicista, dado que esta permite considerar, sólidamente, que el botín aparece en las fuentes como bien del "Estado" y, con ello, enmarcar el estudio dentro del régimen jurídico del patrimonio estatal. Esta tesis encuentra un argumento en la incipiente República con la figura de Publícola ${ }^{9}$, donde se puede apreciar, al menos, la "conciencia" de que existen bienes que "pertenecen" a la comunidad ${ }^{10}$ (populus) y de los cuales depende la existencia de la propia comunidad, "conciencia" que se plasma en la aparición del Erario. En concreto, se nos habla de bienes que se sustraen a los particulares (impuestos) y con los que se enriquece el pueblo (botín).

Tal vez se nos pueda criticar la utilización de términos confusos o poco precisos jurídicamente como conciencia ${ }^{11}$ o pertenencia, sin embargo, lo antedicho exigiría un estudio pormenorizado de la formación como persona jurídica del "Estado", tema que no nos ocupa. No hemos pretendido, por tanto, hablar del sujeto de derecho stricto sensu, sino ver cómo las fuentes atribuyen bienes a la comunidad política romana durante el periodo republicano o, dicho de otro modo, cómo le pertenece el botín de guerra. Por esta razón, pretendemos adentrarnos en la visión iuspublicista al intentar constatar, a través de las fuentes, cómo el pueblo aparece como centro de imputación del botín.

9 Si aceptamos la realidad del testimonio de Plutarco, en tiempos de Publícola (Plut. 22.3), la victoria sobre los sabinos en el año $504 \mathrm{a}$. C. supuso fortalecer al pueblo romano con recursos y prisioneros. A este fragmento hemos de añadir como Publícola (12.3), en materia de impuestos y para evitar suspicacias que lo vinculasen al régimen anterior, permitió al pueblo nombrar cuestores -quaestores-y depositar la recaudación en el templo de Saturno, con el fin de evitar que amigos suyos dispusiesen de los recursos y que estos se depositasen en casas particulares.

10 En este punto entendemos por comunidad lo afirmado por WEBER, Economía y sociedad, 2. ${ }^{a}$ reimp., Madrid: Fondo de Cultura Económica, 2002, de la 2. ${ }^{a}$ ed. en español, 1964 (Wirtschaft und Gesellschaft, Tubinga, 1922), pp. 33, 322 ss. Ahora bien, lo tomamos en el sentido de que aquello que vincula a las partes de la misma no es lo meramente racional (sociedad) sino que existen vínculos afectivos y tradicionales ("cofradía pneumática").

11 Nos referimos a conciencia en el sentido de percatación o reconocimiento, como objeto o cualidad, de algo exterior, tal y como apunta José Ferrater, voz "conciencia", en Diccionario de Filosofía, 1, Barcelona: RBA, 2005, pp. 620-625, en especial 620. Dudamos mucho de que desde el principio se configurase técnicamente de un modo perfecto un concepto jurídico. Quizás sea más probable pensar en una fase previa en la que el grupo como tal tome conciencia, no sólo de sí mismo, sino también de la existencia de bienes que pueden ser comunes a todos los miembros en tanto que necesarios o que puedan enriquecerlos. 
Al abordar los hechos históricos de los cuales obtener el material con el que intentar elaborar nuestra tesis hemos constatado un momento y un hecho concreto que puede actuar como punto con el que poder explicar el antes y el después del tema que nos ocupa. Nos referimos a la toma de Veyes en el año 395 a. C. y a la expresión que aparece en la narración liviana en la que se evidencia claramente la pertenencia in potestatem del pueblo del botín capturado. De este modo, se plasma un modo de entender la relación entre el populus y la praeda. Este año y este acontecimiento, como punto de referencia temporal, nos obliga a estructurar nuestro trabajo en tres puntos: el estudio de la situación anterior a este acontecimiento, lo que supone el uso de la expresión en el contexto de la toma de la ciudad de los veyenses y, por último, la situación jurídica posterior al mismo.

\section{TITULARIDAD PÚBLICA DURANTE LA REPÚBLICA}

\section{La Situación JURídica ANTERIOR AL AÑO 395 A. C.}

Como acabamos de señalar en la introducción, la toma de Veyes marca un punto de referencia que nos lleva, en este apartado, a abordar la cuestión de la titularidad del botín y su patrimonalización en la época anterior a la conquista. Para poder realizar el análisis necesitamos un criterio con el que analizar los textos y, para esta época, hemos pensado que el más conveniente sería el destino del botín, en tanto que el destinatario pueda ser el titular, y atendiendo a dos momentos ${ }^{12}$ : cuando el botín entra en un triunfo ${ }^{13}$ y cuando se dispone de él en el campo de batalla.

Con estos puntos de referencia podremos concluir que el titular es el populus desde el momento en que se agrupan los bienes en el campo de batalla.

Argumentemos la tesis:

a. Cuando se entra de forma triunfal o con ovación en la ciudad con el botín capturado al enemigo

Cuando el botín entra en la ciudad en un triunfo, ca dónde se destina? Para responder a esta pregunta iremos analizando principalmente los testimonios de Livio e iremos descartando entre los posibles titulares: general, soldados, Senado o pueblo.

12 Marianne Coudry. "Partage et gestion du butin dans la Rome républicaine: procédures et enjeux", en Praeda. Butin de guerre et société dans la Rome républicaine, dir. Marianne Coudry y Michel Humm, Stuttgart: Steiner, 2009, pp. 21-27.

13 Georges DumÉZil. La religión romaine archaïque, Paris: Payot, 1966, p. 285, señala que el triunfo, cuando el Senado se lo otorga al general victorioso, es, literamente, "la plus éclatante manifestation de l'entente du dieu et du peuple". HenRI Le BonNIEC, "Aspects religeux de la guerre à Rome", en Problemes de la guerre à Rome, dir. J. P. Brisson, Paris: Mouton, 1969, p. 110, lo define como ceremonia esencialmente religiosa. 
Tomamos nota del hecho de que, desde la caída de la Monarquía hasta el año 395 a. C., parece haber noticias sólo de unos cinco triunfos y ovaciones.

En todos los casos observamos cómo lo que entra con el triunfo o la ovación no se reparte entre los soldados, salvo que se haya hecho antes en el campamento (Liv. 3.20.9), en cuyo caso los soldados entran con su botín con carácter privativo.

Este reparto previo nos hace pensar que los soldados quedan excluidos de la titularidad del botín una vez se ha decidido no repartirlo entre ellos en el campamento tras la batalla.

Eliminado el ejército, queda el Senado, el general o, en todo caso, el pueblo, a través del Erario, como posibles titulares.

Un primer problema surge cuando el botín, o parte de él, se destinase al cumplimiento de un voto, es decir, una promesa de naturaleza religiosa, que realizó el general antes de partir al combate ${ }^{14}$.

En este caso, el magistrado revestido de imperium actuaría como un intermediario entre los hombres y los dioses, y mediante el voto quedaría vinculado y obligado a convertir parte del botín en ofrenda a la divinidad o a destinarlo a la construcción de un templo, transformándolo así en res sacra ${ }^{15}$.

El voto realizado por el general suponía, a nuestro entender, un acto de disposición, como sucedió con Camilo; de este modo es el general quien dispone del botín y garantiza el cumplimiento del voto.

Si esos bienes, por decisión humana, pasan a manos privadas, como es el caso de los bienes prometidos por Camilo, se conserva sobre esos bienes privados la porción consagrada en el voto, y eso se manifiesta claramente cuando se nos dice que dependerá de la voluntad de los privados el cumplimiento de la porción que a cada uno de ellos le ba correspondido y de su obligación religiosa de cumplir el voto.

En este caso hemos de suponer que existe un estadio jurídico anterior no privado y que no se expresa paladinamente en las fuentes en las que el botín no es ni mucho menos privado pero que es susceptible de disposición ${ }^{16}$ por un órgano público que se lo entrega a los particulares.

La parte de la praeda bellica que no se destina al voto y entra en el triunfo es probable que fuese al Erario público, pues como cuenta Dionisio de Halicarnaso en 10.25.3, Cincinato, antes de entrar en Roma como triunfador, mandó separar en el campo de batalla la mejor parte del botín y ordenó que se llevase a Roma ${ }_{i}$ es de suponer que el resto se lo entregó a los soldados.

14 Estos son los supuestos: botín consagrado, Valerio Publícola 509 a. C.; construcción de templo Ceres, Líber y Líbera y organización de juegos y sacrificios por A. Postumio en el año 499 a. C. en cumplimiento de un voto o consagradas en el capitolio Sevilio Prisco en el año 495 a. C. cumplió los votos y consagró los despojos.

15 GeORGE Wissowa. Religion und Kultus der Römer, München: Beck, 1971, p. 385.

16 Fabrizio Fabbrini. La definizione del potere in Roma antica, Roma: Euroma La Goliardica, 1983, p. 47, señala que los magistrados actuarían por delegación. 
Todas las situaciones nos llevan a la misma conclusión: que la titularidad es manifiestamente del pueblo, el lugar donde se deposita es el Tesoro, y es el Senado quien dispone de este.

De ahí que en algunos casos le atribuya parte del botín al general victorioso tras el triunfo, como ocurrió con Cincinato a quien se le ofrecieron tierras, esclavos, así como dinero del botín. Es una manifestación más de que una vez ingresado el botín en el Erario es el Senado quien puede disponer liberalmente de él.

Por tanto, el botín que llega a Roma en triunfo es administrado por el Senado pero no como titular del mismo. Ello supone, por tanto, que otra entidad debe ser la titular. ¿De quién se considera que es el botín ingresado en el Erario? Lo lógico es pensar que es del populus. De hecho, Dionisio de Halicarnaso es claro en 5.47.1 al afirmar que la venta del botín revirtió en el pueblo para recuperar así las contribuciones realizadas con el fin de equipar a los soldados.

De lo dicho se puede inducir que la comunidad política romana tiene conciencia, al menos desde los comienzos de la República, de que participa como grupo de la acción comunitaria ${ }^{17}$ que supone la entrada en combate con otro pueblo, y que pertenece a la comunidad política aquello que entra en la ciudad como producto de dicha actividad.

Considerado que el botín que ha entrado en la ciudad en un triunfo u ovación es del pueblo, cabría hacerse una segunda pregunta: ¿desde qué momento lo adquiere? Podemos avanzar que la entrada en triunfo u ovación no es el momento a partir del cual se adquieren los bienes sino que es anterior: el momento en el que se alcanza la victoria en el campo de batalla.

2. Cuando se dispone del botín en el campo de batalla

La segunda situación a tener en cuenta para inferir datos sobre la titularidad del botín es el momento posterior a la batalla victoriosa. Una vez finalizada, en el campo de batalla se manifiesta o cosifica el botín sobre el que alguien dispondrá: un cónsul ${ }^{18}$, un dictador ${ }^{19} \mathrm{o}$ un tribuno militar ${ }^{20}$, todas ellas magistraturas con imperium en ejercicio de la función militar. Ellos son quienes deciden cuál es el destino del botín al ordenar en ese instante qué debe hacerse con él.

17 Claude Nicolet. Le métier de citoyen dans la Rome républicaine, Paris: Biblioteque des histoires, 1976, p. 142.

18 D.H. 5.39.3 (505 a. C.) ${ }_{i}$ D.H. 5.47.1 (503 a. C.) ${ }_{i}$ D.H. 6.29.4-5 (495 a. C. $)_{i}$ D.H. 6.91.3; 6.92.6; 6.94.1-2 (493 a. C.); D.H. 8.57.1 (488 a. C.) $)_{i}$ D.H. 8.82.4 (485 a. C.); D.H. 9.2.45 (481 a. C.); D.H. 9.16 .8 (478 a. C.) $)_{i}$ Liv. 2.60 .2 (471 а. C.); D.H. 9.56 .5 (469 а. C.); Liv. 3.8.10; Liv. 3.10 .1 (462 a. C.); D.H. 10.21 .6 (459 a. C.); Liv. $3.31 .4(455$ a. C.); D.H. 11.48.3 (449 a. C.); Liv. 4.21.1-2 (436 a. C.); Liv. 4.29.4 (431 a. C.); Liv. 4.53 .10 (410 a. C.)

19 D.H. 10.25.1 (458 a. C.); Liv. 3.29 (458-457 a. C.); Liv. 4.29.4 (431 a. C.); Liv. 4.34.4 (426 a. C.); Liv. 4.47.4 (418 a. C.); Liv. 5.14.7.

20 Liv. 3.3.8 (466 a. C.); Liv. 4.49.9 (414 a. C.); Liv. 4.59.8-10 (406 a. C.); Liv. 5.16 .7 (397 a. C.). 
Precisamente, Polibio ${ }^{21}$ nos narra cómo, tras la toma de Cartago Nova, los romanos "amontonaron en el ágora los bagajes de los soldados cartagineses, así como los ajuares de los ciudadanos y los obreros. Según el uso romano, los tribunos lo distribuyeron entre sus legiones [...] [Y]a describimos ${ }^{22}$ cuando tratamos la constitución, que nadie puede escamotear nada del botín, sino que han de ser fieles al juramento que prestan cuando se juntan por primera vez en el campamento".

El historiador griego nos narra que, según el uso romano, el botín se amontona y, con el fin de evitar los efectos perniciosos que una captura desordenada de bienes podría provocar, no se puede adquirir directamente por el soldado. El juramento es el medio por el que se vincula al soldado al general y a la República y, por tanto, puede o no recibir parte del botín "si llega la oportunidad" (Pol. 10.17.5).

Si observamos el estricto régimen al que se encuentra sometido el botín, en el sentido de que la inicial y primera decisión sobre lo que se debe hacer depende de un magistrado con imperium, podríamos pensar que, dado que el general dispone del botín, podría ser suyo o del ejército.

Esto no parece del todo ajustado a los testimonios, pues se observa, por un lado, que en Liv. 2.42.1 $1^{[23]}$ se nos habla de la mezquindad del Senado -malignitate patrum - que dejó sin botín a los soldados, lo que evidencia que el Senado podría intervenir, al igual que el general, sobre la decisión del destino del botín y que, en caso de ser aquel quien pueda decidir con facultad de disposición, excluye que sean los soldados o el general los titulares del botín.

Visto pues que el Senado puede decidir sobre el destino, veamos ahora cuál suele ser éste cuando quien ejercita su facultad de disposición es el general siguiendo los testimonios de Livio:

i. Que se entregue a los soldados, sea como bienes (D.H. 6.29.4-5; 6.91.3, 9.16.8; Liv. 4.47.4; 4.47.9-10; 5.16.7; 5.19.8), sea como capital producto de la venta (D.H. 5.47.1; Liv. 5.16.7).

ii. Que vaya al Tesoro, previa venta del mismo en subasta (D.H. 6.29.4-5, en este caso, ordena que no se lleve; D.H. 8.82.4; Liv. 4.53.10).

iii. Que se recupere lo que fue capturado por los enemigos y en su caso se devuelva a sus legítimos dueños (Liv. 2.64.3-4; 3.7.12; 3.8.10; 4.29.4).

iv. Que se consagren una parte de los despojos (D.H. 10.25.1).

v. Que se premie a los soldados (D.H. 9.6.18; Liv. 4.34.4).

A nuestro modo de ver, de los diversos destinos se intuye que el botín ni es del general, el cual parece que tenga funciones más bien administrativas, ni mucho menos es de los soldados, lo cual se observa no sólo en que es el

23 Accensaque ea cupiditas est malignitate patrum, qui deuictis eo anno Volscis Aequisque, militem praeda fraudauere 
general quien decide sino también en que los soldados pueden verse privados de él, con gran enojo, como veremos.

Que no es del ejército parece evidente, dado que los testimonios dicen generalmente que quien captura o vuelve con gran botín es el general (D.H. 9.35; Liv. 3.3.8). En el caso de expresiones como "dueño de un enorme botín" referidas al general en su vuelta a la ciudad, más parecen literarias que jurídicas (Liv. 3.8.10; 8.19.9).

Cuando el botín se entrega a los soldados no se hace porque se piense que sean los titulares del botín, sino por razones de carácter social, político o de reconocimiento por la actuación en combate (Liv. 3.29; 4.34), como veremos en el desarrollo del apartado correspondiente.

Como vemos, determinar cuál es el destino no aporta todos los datos necesarios para resolver las dudas sobre la titularidad. A este fin nos puede ayudar atender el porqué, es decir, por qué se envía al Tesoro o se reparte a los soldados.

Los testimonios al respecto parecen claros ya que, normalmente, cuando el botín va al Tesoro suele deberse a la escasez de recursos o sencillamente a que así se considera más adecuado políticamente (Liv. 3.8.10), en cuyo caso lo que suele entrar en conflicto son los intereses entre patricios y plebeyos, quienes, como soldados, esperan obtener beneficios con la captura.

Con el ingreso en el Tesoro se suele decir por los historiadores que se enriquece la patria (D.H. 9.2.4-5, Plut., Pub. 23.2, y en el mundo de la comedia, Plaut., Amph. 190), lo cual resulta indicativo de que el botín, en términos generales, debió constituir un bien con el que el populus se beneficiaba.

Estos argumentos no son definitivos para hablar de una clara titularidad pública en sentido técnico; pero es posible pensar que el botín, cuando va al Tesoro, se entiende que es un bien que debe redundar en beneficio de los miembros de la comunidad, y es aquí donde se empieza a perfilar que el botín sea una res in patrimonio populi: como un bien con el que el pueblo se beneficia.

Cosa distinta es que no se levantasen suspicacias entre la población al ver cómo un producto de la guerra, que podía beneficiarla directamente y satisfacer con ello necesidades inmediatas, como eran las deudas, quedaba en manos del patriciado a través del Senado con una reversión nula o casi nula sobre la población plebeya que así habría visto sus penurias ${ }^{24}$. Esta cuestión no es, como puede apreciarse, jurídica sino política.

Cuando el beneficiario del botín es el ejército-ciudadano, se benefician los plebeyos, que ven en el botín un modo de enriquecerse y de aliviar sus penurias ${ }^{25}$. Sin embargo, esa necesidad no se convirtió en un derecho, sino que 
siguió siendo una aspiración al botín ${ }^{26}$. Por tanto, no es suyo ${ }^{27}$, sino que todo depende de un acto de magnificencia y consideración del general que se hará más evidente a lo largo de la República, acto de magnificencia y liberalidad que responde a tres razones: 1) aliviar la pobreza y las cargas, debidas a las contribuciones, que la guerra suponía para los soldados, especialmente los de clase más humilde ${ }^{28} ; 2$ ) recompensar el valor de los soldados ${ }^{29}$, y 3 ) congraciarse políticamente con la plebe en un momento de tensión social ${ }^{30}$.

El botín, por consiguiente, se utiliza para reconocer acciones militares o dar respuesta a determinados problemas políticos y sociales, pero en todo caso, los soldados son los destinatarios de un bien cuyo titular ni es el general ni es el Senado.

Como consecuencia de lo que acabamos de exponer, desde el momento en que se vence en batalla, el pueblo romano se puede considerar poseedor del botín, y no los soldados que, por razón de su juramento militar ${ }^{31}$, se ven

botín un medio con el que financiarse fundamentalmente con el gran desplazamiento de capital y riqueza que supone la conquista.

26 Liv. 4.9.8: 4.31.6; Cic., Ep. ad Cic. 12.12.3

27 En sentido opuesto, Vogel afirma que el derecho de estos al botín se justifica en Polibio, Historias, trad. M. Balasch, Barcelona, 2000, 10.17.1; D.H. 4.19; Liv. 9.31.16 (se lanzaron a por el botín de ganado); 40.5.6; Caes., de BG. 2.24 (salir a hacer botín), 4.34 (César invita al saqueo); Pol. 10.15.4 (no podían lanzar a recoger el botín hasta recibir la señal), 8 (recibida la señal, se lanzaron a por el botín), y sin embargo, 9 (dice que mandó reunir el botín que correspondía a cada manípulo); 16.1 (según el uso romano lo distribuyó entre sus legiones), 2-9 (se reúne y se divide y no se puede escamotear nada del botín por su juramento). Dice 17.2 que, entre las naciones, el botín pertenece a quien lo captura, lo que no ocurre en Roma, para evitar, precisamente, los desórdenes en la captura del botín. El botín, si llega la oportunidad, será repartido entre todos por igual. Destaca también en D.H. 7.63.2 el discurso contra de Decio contra Marcio (Coriolano) se dice que "Sin duda todos sabéis que la ley ordena que los botines de guerra que nos está permitido coger por nuestro valor sean públicos, y que no se adueñe de estos no ya un particular, sino ni siquiera el mismísimo general del ejército; el cuestor se encarga de ellos y los subasta, y entrega el dinero al erario público. Y esta ley, desde que habitamos la ciudad, no sólo nadie la ha violado sino que ni siquiera se le ha reprochado el no ser buena ley. Pero este Marcio es el primero y el único que, despreciándola, a pesar de que existía y era válida, consideró oportuno, plebeyos, apropiarse de nuestro botín común el año pasado, no hace mucho. En efecto, cuando hicisteis una incursión en el territorio de los anciates y os apoderasteis de muchos prisioneros, muchos rebaños y mucho trigo y de muchos otros bienes, ni los mostró al cuestor, ni los vendió personalmente y llevó el dinero al erario público, sino que distribuyó el botín entre sus amigos (Ver Discurso de Catón). Esta acción, afirmo, es sin duda prueba de tiranía...".

28 DH. 5.47.1 Venta de botín con el que contribuir a compensar las contribuciones con las que se equiparon los soldados. Liv. 2.25.2: inde paulum recreatus egem miles con el que se tenían que resarcir los soldados más pobres; D.H. 6.29.4-5.

29 D.H. 9.16.8; Liv. 3.29.

30 D.H. 9.2.4-5.

31 Pol. 6.21.1; 6.33.1; Liv. 22.38.3; Aul. Gel. 16.4; Nicolet, Le métier, p. 141, destaca el vínculo que supone este juramento del soldado con el general, la República y sus conmilitones. Al 
obligados a entregar todo a quien ostente el mando en ese momento. Sin embargo, al pueblo romano no le corresponde la administración del mismo, sino que en su nombre lo hacen los generales en el mismo campo de batalla.

\section{La tOMA DE VEYes EN El aÑo 395 A. C.: ANÁLISIS DE LA EXPRESIÓN IN POTESTATEM POPULI ROMANI}

Visto pues que el pueblo es quien adquiere la praeda, nos acercamos ahora al texto sobre el que pivota la estructura argumental de este apartado y que es un fragmento de Livio en el que aparece por primera vez para la época republicana una expresión que resulta tremendamente expresiva, in potestatem populi Romani, con la que Livio se refiere al botín capturado a Veyes en el año 395 a. C.

Contextualizando el acontecimiento que narra Livio, hemos de situarnos en los momentos anteriores y posteriores a la inminente caída de Veyes; momentos en los que plantea una serie de cuestiones acerca de qué hacer con el botín:

1) Si se deja en manos de la población o sólo de los que participan en la guerra.

2) Cómo cumplir el voto que Camilo hizo a Apolo, antes de entrar en guerra, de la décima parte del botín y, en su caso, si debe ser cumplido por la población, la cual habría capturado el botín.

3) Si se incluyen las tierras capturadas dentro de esta décima parte ${ }^{32}$.

respecto Salvatore Tondo, "Sacramentum militiae nell'ambiente culturale romano", en Studia et documenta historiae iuris, vol. 29, 1967, pp. 1-123; "Sacramentum militiae", en Studia et documenta bistoriae iuris, vol. 30, 1968, pp. 376-396, para rebatir la crítica de ARnaldo Momigliano, en Journal of Roman Studies, 57, 1967.

32 Concretando más los hechos, el testimonio podemos contextualizarlo históricamente en el año 395 a. C. tras la toma de Veyes, y la cuestión que se suscitó fue cómo satisfacer el voto de Camilo con el que había iniciado la campaña definitiva contra Veyes y por la que había ofrecido la décima parte del botín a Apolo -Liv. 5.21.1-, ya que con este voto no sólo se obliga Camilo, sino también el pueblo. El problema se suscitó anteriormente cuando se discutió en el Senado, antes de realizar el voto y tomar la ciudad, qué se podía hacer con el botín: se manifestaron dos opiniones: 1) si permitir, por acuerdo del pueblo, el saqueo de la misma por quien quisiese y, de ese modo, ganarse la voluntad de la plebe $y$, con ello, prestar ayuda a los que estaban arruinados por los impuestos y que disfrutaran de ese modo de las riquezas del botín quienes estaban exhaustos por la guerra, posición defendida por Publio Licinio, o 2) la posición defendida por Apio Claudio, quien afirmaba que si era una decisión irresponsable, injusta y desconsiderada, puesto que era de impiedad que el botín pasara al Tesoro, agostado por las guerras, que al menos con el botín se abonase la paga y se suavizase de ese modo la carga tributaria de la plebe. Con el fin de que el Senado ganase popularidad se optó por la opinión de Licinio y, con ello, tras la venta por subasta de los hombres libres, cuyo producto pasó al Tesoro, lo que enervó a la plebe, esta se llevó el botín. Una vez capturado el botín por la plebe y celebrado el triunfo de Camilo y efectuada su dimisión, es cuando se plantea el problema del cumplimiento del voto, pues el botín estaba en manos de la plebe y, según Livio, los pontífices, ocupados en esta cuestión, estimaron que el pueblo debía liberarse de su compromiso sagrado, si bien 
A partir de aquí nos encontramos con nuestra expresión que es, por consiguiente, un perfecto punto y seguido, pero definitorio, para analizar la dimensión iuspublicista de la titularidad del botín de guerra.

La literalidad del fragmento es la siguiente: Cum ea disceptatio, anceps senatui visa, delegata ad pontifices esset, adbibito Camillo visum collegio, quod eius ante conceptum votum Veientium fuisset et post votum in potestatem populi Romani venisset, eius partem decumam Apollini sacram esse (Liv. 5.25.7).

Este testimonio, en su contexto y desarrollo histórico, nos lleva a articular nuestra argumentación atendiendo a tres aspectos sobre la toma de Veyes: quién es el titular, cómo se sustancia ese poder, y las razones por las que aparece esta forma de expresión y que formulamos del siguiente modo:

a) La discusión que se suscita en el Senado a raíz de que el dictador eluda su decisión de qué hacer con el botín y los discursos de Publio Licinio y Apio Claudio sobre qué hacer con el botín.

b) La utilización por primera vez de la expresión in potestatem populi Romani para referirse a la situación jurídica en la que se encuentra el botín. Las preguntas que hemos de dilucidar en este segundo punto son claras: 1) qué significa o cómo entender esta expresión, y 2) por qué la utiliza justo tras la toma de Veyes.

c) Por qué Livio usa de ella en este momento y no lo hace antes.

Veamos estos puntos:

En primer lugar, la discusión que se suscita en el Senado, a causa de que el dictador Camilo ha eludido cualquier decisión respecto a la disposición sobre el botín que se pueda capturar con la conquista de Veyes, muestra la concepción de bien público que tiene el botín en esa época y de su pertenencia al pueblo romano.

El Senado, ante la circunstancial negativa de Camilo, dictador y por tanto investido de todo el imperium, deberá decidir cómo se reparte en su caso el futuro botín conseguido tras la conquista segura de Veyes.

No se discute pues quién es el titular del botín sino: por un lado, quienes tienen facultad de atribución del mismo y, por otro lado, habiendo recaído esta sobre el Senado, cómo la va a llevar a efecto teniendo en cuenta las apetencias de los distintos posibles beneficiarios y las circunstancias políticas que permitirán al Senado una mayor o menor capacidad de maniobra.

no era fácil obligar al pueblo a que presentase el botín referre praedam populum y, con ello, cumplir el voto. Se tomó una primera decisión, a saber, que quien quisiese librarse a sí mismo y a su casa, tasase su propio botín y entregase una décima parte al Tesoro -cum sibimet ipse praedam aestimasset suam, decimae pretium partis in publicum deferret- e hiciese una donación en consonancia con la dignidad del pueblo romano. Sin embargo, lo que enerva a Camilo es que el diezmo sólo sea de los bienes muebles y no de la ciudad y del territorio. Planteada esta cuestión ante los pontífices es cuando estos, aconsejados por Camilo, deciden que quod eius ante conceptum votum Veientium fuisset et post votum in potestatem populi Romani venisset, eius partem decumam Apollini sacram esse. 
En el interior del Senado surgieron dos posturas, una defendida por Publio Licinio y otra por Apio Claudio. Aquel entendía que el Senado debería decidir lo siguiente: que, si estaba de acuerdo el pueblo -palam placere populo-, quien desease participar del botín fuese al campamento de Veyes (Liv. 5.20.4). Por el contrario, el discurso de Apio Claudio defiende que el botín completo se entregue al Tesoro, que está exhausto. Sin embargo, entiende que a pesar de que el Senado no ha sido en otras ocasiones debidamente consultado y que, si en este caso y por razones del voto ${ }^{33}$, parece que no sería posible entregarlo de manera absoluta al Erario, a pesar de que está exhausto, al menos que la distribución entre el pueblo se haga de manera justa, de forma que sirva para paliar las cargas de la guerra de manera igualitaria -eius enim doni societatem sensuras aequaliter omnium domos, non auidas in direptiones manus otiosorum urbanorum bellatorum praerepturas (Liv. 5.20.5)-.

Las consecuencias que se pueden extraer de esta discusión son importantes, pues la misma evidencia, por un lado, que la decisión sobre la disposición del botín está en manos de los órganos públicos, bien del general, bien del Senado y, por otro, que, en todo caso, el botín se compone de bienes que aprovechan al pueblo, el cual no dispone de ellos directamente pero se considera que son bienes que le corresponden como populus y que, además, le benefician.

La discusión constituye un punto de inflexión sobre el modo de favorecer al pueblo. Generalmente, la plebe desea que el botín se reparta entre los soldados, porque así participa de forma directa e inmediata en él mientras que el patriciado y, por tanto, el Senado desean que vaya a parar al Tesoro, de manera que sea el Senado en el futuro quien abra la vía de distribución según las necesidades de Roma en cada momento. Muy frecuentemente, la plebe verá esto como una manera de arrebatarle lo que ella consideraba como suyo, entendiendo que las distribuciones posteriores desde el Tesoro difícilmente le

33 Es curioso que Apio Claudio, aunque pueda parecer un recurso retórico, diga que sería semel nefas, con lo que nos introduce en lo que veíamos en un artículo anterior sobre el templo de Saturno y su relación con el Tesoro, razón que hay que buscarla, no sólo en la política, sino también en el hecho de que existe un factor religioso, dado el parentesco existente entre Ops y Saturno y, con ello, los bienes del pueblo adquieren una cierta dimensión religiosa como bienes necesarios para la subsistencia del pueblo colocándolos bajo la protección de un dios que, precisamente, representa la abundancia, la paz, etc. El hecho de que se deposite en los sótanos del templo se justifica porque era una deidad tectónica conectada con mundus. Este mundus aparecería desde tiempos antiguos como un silo comunitario en el que se depositaban las primeras semillas y espigas, simbolizando con ello la acumulación de provisiones. Estaba ubicado en el centro del espacio urbano, por tanto, en el lugar más protegido: en definitiva, el tesoro de la comunidad. Se entiende pues que de la Regia, y por tanto de Ops, se pasase al templo de Saturno, dado que son deidades vinculadas y asociadas a la riqueza y a la prosperidad del pueblo; riqueza y prosperidad que depende, entre otras cosas, de los recursos obtenidos como botín de guerra y porque en las Opalia, Ops se desplazaba de su lugar originario en el Foro al Ara Saturni. 
beneficiarán. En el texto, Livio manifiesta, precisamente, que la decisión tuvo como objetivo congraciarse con la plebe.

Por tanto, se puede apreciar con claridad que el problema no es tanto considerar que al pueblo, entendido como comunidad, le corresponda o no el botín y que aquello que se captura en acto de guerra debe, de un modo u otro, redundar en su beneficio, sino que las divergencias se hallan en el modo de disponer y el destino que se pueda dar a esos bienes; en este caso, que directamente aproveche a los cives o sirva a los cives para disminuir la carga fiscal mediante su ingreso en el Tesoro.

Luego, en lo que concierne a la utilización de la expresión in potestatem populi Romani vemos que sirve para sustanciar el poder que el pueblo tiene sobre el botín.

Con esta expresión, Livio parece querer decir que el botín se encuentra bajo el dominio o poder del pueblo romano (D. 48.4.4 pr.), concretamente, en un sentido objetivo tal que: die Gewalt des Volkes -senatus populi potestatem- ${ }^{34}$ con el que significar una relación jurídica ${ }^{35}$ fundada en la potestas.

Ahora bien, si el término "poder-potestatem" puede ser ambiguo por las connotaciones que se pueden derivar de él ${ }^{36}$, otras dos expresiones utilizadas en otros pasajes del historiador pueden ser bastante descriptivas en tanto permiten una buena intelección del objeto significado dada la utilización de sum en un sentido patrimonial ${ }^{37}$.

Estas expresiones son: a) alia omnis praeda populi Romani esset, referida a la parte del botín que corresponde a los romanos y que no incluye los muros, las ciudades, los suelos y los campos entregados, en este testimonio, a los etolios; $\mathrm{y}_{\text {, }}$ b) praeda populi Romani est respecto a todo lo que perteneció a Sífax, él mismo, su esposa, su reino, sus ciudades y los hombres que las habitan ${ }^{38}$.

Llegados a este punto hemos de concluir que la potestas aparece en las fuentes literarias como el primer modo con el que significar y fundar la situación de

34 KarL-ERnSt GeORgeS. Ausfübrliches lateinisch-deutsches Handwörterbuch 2, reimp., Darmstad: Wissenschaftliche Buchgesellschaft, 2003, pp. 1812-1814, en especial 1813. Liv. 5.20.3, referido a la caída de Veyes in potestate populi romani. Liv. 45.16.7; Liv. 45.41.4. En Liv. 8.19.12 se refiere a los fundanos, ciudadanos romanos, que no dudan, como acto de sumisión, en afirmar que hombres y tierras estarán in potestate populi Romani esse futuraque.

WolfGang KunKel. Staatsordnung und Staatpraxis der römischen Republik, München: Beck, 1995, p. 22; Manuel Hernández Tejero, "Sobre el concepto de potestas", Anuario de Historia del Derecho Español, 17, 1946, pp. 605-624, sobre la transposición al ámbito público del privado. Ludwig V. LuBTOw, "Potestas", en Realencyclopädie der Classischen Altertumswissenschaft, 43, 1953, pp. 1040-1046; Luigi Capogrossi Colognesi, "Potestas", en Novissimo Digesto italiano, 13,1966, pp. 507-510.

36 KunKel, Staatsordnung, pp. 21-22

37 D. 50.16.15. FeRnándEZ DE BuJÁN, Derecho público, p. 251.

38 Liv. 26.24.11 y Liv. 30.14.9, respectivamente. 
patrimonialización que la comunidad romana, en cuanto populus, tiene sobre el botín como bien propio.

Ahora bien, ¿cómo entender que el populus tenga esa potestad?; ¿cómo entender "populi Romani" en la referencia de Livio? Creemos ${ }^{39}$ que el mejor modo de interpretar esta expresión sería, simplemente, como un conjunto organizado, expresado mediante una fórmula unificante y no como un ente ideal "in cui sia stata unificata la pluralità dei Quirites". Esto es, creemos que Livio, con la expresión populi Romani, se estaría refiriendo a un conjunto organizado, formado por los miembros ${ }^{40}$ de una comunidad autónoma -como sui iuris, dice GANDOLFI- ${ }^{41}$, reunidos o unidos, relacionados entre sí y que, como tal pueblo autónomo, se relaciona con otros pueblos que están in sua potestate ${ }^{42}$, es decir, que son autónomos y están en paridad con el pueblo romano.

Ser un pueblo in potestate sua, siguiendo con la interpretación de GandOL$\mathrm{FI}$, nos permite dar un paso más en la interpretación de nuestra expresión al adentrarnos en la condición del pueblo romano para poder ser considerado titular de esos derechos o bienes.

Es Livio ${ }^{43}$ precisamente quien nos refiere una fórmula arcaica para el caso de rendición de la ciudad sabina de Colacia, y que reza del siguiente modo: El rey pregunta a los legados de la ciudad: Estne populus Collatinus in sua potestate?; a lo que contesta el legado: Est. Sigue preguntando el rey: Deditisne vos populumque Collatinum, urbem, agros, aquam, terminos, delubra, utensilia, divina bumanaque omnia, in meam populique Romani dicionem?; Dedimus, contesta el legado.

Dejando de lado la cuestión sobre el poder del rey, parece claro que aquel pueblo que está in sua potestate se entrega a otro pueblo que está, a su vez, in sua potestate ${ }^{44}$ (como dice Capogrossi ${ }^{45}$, "perduta la loro sovranità, siano venuti a trovarsi in una situazione di soggezione nei confronti di un altro Stato"). Tras la rendición, esa entrega supone la transmisión al pueblo de aquello que era del pueblo capturado o que formaba parte de él: bienes muebles e inmuebles y personas, lo cual constituye el botín que queda bajo el poder -dicio ${ }^{46}$ - del pueblo romano.

39 Riccardo Orestano. Il problema delle persone giuridiche in diritto romano, Torino: Giappichelli, 1968, p. 206. Al respecto también Catalano, Populus Romanus Quirites, pp. 98, 105, considera que la expresión populus Romanus es una simplificación de la expresión populus Romanus Quirites, tal y como aparece en Liv. 1.32.6, con la que se indica el conjunto de ciudadanos romanos.

40 Werner Suerbaum. Von antiken zum frümittelalterlichen Staatbegriff, Münster: Aschendorffsche Verlagsbuchhandlung, 1961, pp. 3-4.

41 Giuseppe Gandolfi. "Spunti di diritto internazionale in Tito Livio", A.G. 147, 1954, pp. 7-49, en especial 15.

42 Gandolfi, Spunti, p. 14, referido a la interpretación del pasaje de Liv. 1.38.2.

43 Liv. 1.38.2.

44 La expresión no debe resultar extraña si atendemos a Cicerón, quien atribuye en de legibus 3.28 la potestas al pueblo: potestas in populo, auctoritas in senatus.

45 Capogrossi, Potestas, p. 510.

46 Walde-Hofmann, dicio (ditio), p. 347; GeOrGes, dicio (ditio), p. 2133 
Dicho de otro modo: que dejase de estar bajo el poder - potestas- del pueblo vencido para estar bajo el poder -dicio- del pueblo romano (aunque aquí se añade el rey).

Se puede pues decir que el fundamento por el cual el pueblo romano hace suyos los bienes capturados es el ser consciente de la condición de comunidad autónoma que está in potestate sua y que, como tal, tiene el poder que antes tenía la comunidad vencida sobre los bienes que componen el botín de guerra para convertirlos en patrimonio propio.

De lo afirmado hasta este momento podemos entresacar las siguientes conclusiones:

1. El hecho de que Livio utilice la expresión in potestatem populi y que luego utilice el verbo sum para expresar este significado evidencia que Livio no está utilizando un concepto técnico jurídico estricto, lo cual supone que no se llegó a consolidar técnica y formalmente un término con el que designar a la institución del botín como res in patrimonio populi.

Aunque no exista un concepto técnico estricto sobre la titularidad de los bienes que constituyen el botín, sí que se entrevé claramente la idea de una comunidad que se proyecta como propietaria de los bienes obtenidos; no se proyecta como un ente abstracto o que se construye por encima del conjunto de los bienes que la componen, sino, precisamente, como tal conjunto de miembros que forman la comunidad real a relacionar con el botín, el cual es, a su vez, un conjunto de bienes que se le deben atribuir.

A este concepto de comunidad se le une la condición de sui iuris o in potestate sua, de forma que lo que era de una comunidad in potestate sua ahora pasa a ser de otra comunidad que también es in potestate sua.

2. La combinación populus Romanus con est o esset indica la naturaleza pública de la relación jurídica y no privatística ${ }^{47}$.

3. El populus Romanus ${ }^{48}$, como conjunto de miembros de una comunidad autónoma -in potestate sua-, aparece como centro de imputación de facultades de

UGo Coli. "Sul parallelismo del diritto pubblico e del diritto privato nel perido arcaico di Roma", en Studia et documenta bistoriae iuris, 4, 1938, Exceptum 25, n. 47, citado de OuIs RobledA, "La capacidad jurídica del populus Romanus", en St. Grosso 3, Torino: Giappichelli, 1968, p. 109.

48 Otro problema se encuentra en el hecho de que el populus Romanus no se puede considerar como un ente abstracto sino como una pluralidad de individuos, lo que dificulta entender a una mente moderna cómo se articula jurídicamente la adquisición del botín de guerra. Quizás, como afirma De MARTINO, la ciudad-Estado tiene un fundamento legal, si bien no se proclama en ley alguna que el sujeto del Estado ciudadano es el pueblo romano de los quirites unido en una colectividad, una especie de societas, como la koinonía griega. Esta colectividad se observa en la misma terminología con la cual se designa a la ciudad-Estado: res publica como res populi. Esta fórmula tenía como punto de mira inicial el aspecto material de la ciudad y, posteriormente, lo idealizó en una suma de poderes y derechos. Si tal vez se utilizan fórmulas como populus plebesque o Populus Sentusque Romanus, ello dependía de la tendencia de las clases a dar un mayor o menos colorido político a su presencia y fuerza, 
naturaleza jurídica y, con ello, el populus tiene capacidad jurídica ${ }^{49}$ pues, como tal, somete a su poder aquello que estaba bajo el poder del pueblo vencido.

4. Que, según Livio, a inicios del siglo IV a. C. ya existe una clara noción de que los bienes capturados al enemigo son bienes que están bajo el poder, entendido patrimonialmente (como est-esset), del pueblo romano y como resultado, en este caso, de un acto bélico de adquisición.

5. Por último, que el botín de guerra se considera en este caso como bien propio de todos y cada uno de los miembros que forman parte de la comunidad política, esto es, de todos y cada uno de los cives que forman el populus.

Dicho esto, los hechos narrados por Livio nos obligan a hacer un paréntesis en este momento, pues existe un punto de la narración que puede ser confuso al permitir una interpretación privatística de la adquisición del botín y que es necesario aclarar.

Se trata del modo en que se refieren los pontífices a la contribución voluntaria al voto ${ }^{50}$ con la décima parte del botín cuando este está en manos de los particulares a los que se les ha permitido tomar el botín.

El testimonio dice: cum sibimet ipse praedam aestimasset suam, decimae pretium partis in publicum deferret, donde se observa una clara noción de publicus por contraposición a lo privado que se corresponde con el cum sibimet ipse praedam aestimasset suam.

Ahora bien, cacaso la expresión praedam suam indica que la praeda se adquiere como occupatio? A nuestro modo de ver, no parece que la occupatio sea la mejor forma de interpretar la acción de apropiación de la plebe, y ello por dos razones: la primera, referida al voto que realiza Camilo sobre el botín, vinculando con ello la comunidad ${ }^{51}$ y que evidencia una capacidad de disposición pública; la segunda razón se demuestra porque es en el Senado donde se discute qué hacer con el botín, pudiendo disponer de él a priori.

pero no modificaba la idea de pueblo como sujeto unitario. FranCESCO DE MARTINO, "La costituzione della città-stato", en Storia di Roma. Roma in Italia, dirs. Arnaldo Momigliano y Aldo Schiavone, Torino: Einaudi, 1988, pp. 345-365, en especial 365.

49 RobledA, La capacidad jurídica, pp. 103-113.

50 La voluntariedad se justifica por el hecho de que el voto es, según J. Guillén, Urbs Roma III, Salamanca: Sígueme, 2004, pp. 125 ss., "el ruego dirigido a los dioses con la promesa de realizar algo en su nombre, concebido jurídicamente como un contrato, por el que se exige la donación propuesta a la divinidad como condición previa a nuestro acto (daut dem, fac utfaciam)". Por él, aparentemente, no se vincula el pueblo sino quien lo realiza y, en su caso, el heredero. Sin embargo, no deja de ser curioso que Camilo se manifieste dolido por el hecho de que el pueblo no se desligue del vínculo sagrado. Etimológicamente, según DumÉZIL, La religión, p. 91, proviene de uoueo, del védico vaghat que significa "quien ofrece un sacrificio".

51 EISENHUT, voz "votum", en Realencyclopädie der Classischen Altertumswissenscbaft, Supp. 14, 1974 pp. 964-973, en especial 965. En el caso del voto existe una clara dimensión pública o, si se quiere, comunitaria, pues el magistrado con imperium podía vincular a los ciudadanos, tal y como al parecer puede deducirse de Liv. 21.62.10; 22.33.7; 27.11.6. 
De todo ello concluimos que hay razones más que fundadas para considerar que la actuación de la plebe al apropiarse del botín no puede interpretarse como un acto puro de occupatio al ser esta una opción que se atribuye sometida siempre a los actos de disposición de los órganos públicos: general y Senado.

Llegados a este punto, es el momento de dar respuesta a la siguiente cuestión: ¿por qué no utiliza Livio la expresión in potestatem populi Romani referida al populus como centro de imputación del botín antes de la toma de Veyes? ¿supone Livio que se ha producido realmente algún cambio jurídico?

A nuestro entender, al utilizar por primera vez esta expresión, Livio quiere marcar una inflexión de tipo político al hacer evidente que se está comenzando a superar el conflicto patricio-plebeyo y que, por tanto, nos encontramos ante una nueva era sociopolítica en Roma, de acercamiento entre los dos poderes que constituyen el populus.

La discusión en el Senado y la aceptación por parte de este de la realidad que constituye la necesidad de premiar a los plebeyos a pesar de que, como remarca Claudio, el Tesoro está exhausto, indica hasta qué punto el Senado es consciente de que debe compartir el botín con la plebe y que sería obrar contra justicia, y con toda seguridad poco prudente, prescindir de las necesidades de los plebeyos.

Hasta ese momento, los textos nos muestran que la guerra y su beneficio, en forma de botín, vienen marcados por las luchas patricio-plebeyas; especialmente como consecuencia de la situación de penuria en que se encuentra gran parte de la plebe y de las eternas luchas por la tierra.

Los plebeyos pobres, cuando forman parte del ejército, ven en el botín una vía para paliar su depauperada situación económica que la guerra agrava al impedirles cultivar su tierra y tener que costearse la campaña militar.

De hecho, la esperanza de obtener un botín y las levas militares se utilizan muchas veces como arma para granjearse el apoyo plebeyo en la lucha política. Parece evidente que no era del agrado plebeyo que el botín fuese al Tesoro, controlado por el Senado y la clase patricia y, con ello, que nada o casi nada revirtiese en el pueblo para contribuir a paliar su situación.

La posibilidad de que el botín pueda destinarse al Tesoro o repartirse entre los soldados no cambia en nada que sea la comunidad política romana la beneficiaria del mismo, si entendemos que fórmulas como populus plebesque o Populus Sentusque Romanus se refieren a la misma comunidad.

El Tesoro o el ejército no son más que los destinatarios inmediatos, sujetos de un acto de disposición por parte de los órganos de la comunidad que tienen la potestad sobre el botín; comunidad que, hasta este momento, está sufriendo las consecuencias de la tensión social, política y económica entre patricios y plebeyos.

Justo con la toma de Veyes, la situación entraba en la fase decisiva para ser superado el conflicto patricio-plebeyo. 
Guarino $^{52}$ señala cuatro acontecimientos al efecto, de los cuales nos interesan dos:

1. El decreto del Senado por el que se instauró una soldada con cargo al Erario para cubrir los gastos militares tras la toma de Anxur ${ }^{53}$ en el año 406 a. C., apenas diez años antes de la toma de Veyes.

2. La toma de Veyes supuso que la plebe apartase la victoria sobre el patriciado en pro de una victoria de compromiso con la que se esperaban pingües beneficios para la plebe y que supuso la espita que inició la conquista romana de Italia ${ }^{54}$.

Zamorani ${ }^{55}$ ha visto un hábil movimiento de los unionistas, frente a quienes defendían el separatismo entre patricios y plebeyos, en la decisión de instaurar la soldada y la estocada mortal al separatismo en la batalla definitiva de Veyes. Según este autor, como Guarino, la unión, esencialmente militar, se cimenta en razones de tipo económico, como son la expectativa de botín y de tierras; una unión que trasluce la disputa entre unionistas y separatistas.

Esta situación, unida al destino que se le da al botín de guerra, y que hemos visto al inicio de este apartado tras la consulta de Camilo al Senado, son razones más que suficientes para entender por qué Livio utiliza en este momento la expresión in potestatem populi Romani.

Con ello, el historiador no pretende evidenciar una situación jurídica nueva, sino expresarse de un modo acorde con los nuevos vientos unionistas que soplan en pleno conflicto patricio-plebeyo.

\section{Situación JuRídica posterior al año 395 a. C.}

A diferencia de lo que ocurría en el periodo anterior a la toma de Veyes, podemos observar cómo se produce un cambio sustancial en la percepción que se tiene del botín como res que pertenece al pueblo.

Se va a producir una concreción jurídica de la realidad que, sin llegar a formar un término técnico en sentido estricto, sí que se hace patente la noción de bien perteneciente al pueblo.

Esta nueva percepción, probablemente como consecuencia de la progresiva superación de las diferencias sociales, se evidencia en el orden cronológico de los acontecimientos históricos.

Veamos la secuencia de los testimonios:

52 Antonio Guarino. La rivoluzione della plebe, Napoli: Liguori, 1975, p. 228.

53 Liv. 4.59.11: Additum deinde omnium maxime tempestiuo principum in multitudinem munere, ut ante mentionem ullam plebis tribunorumue decerneret senatus, ut stipendium miles de publico acciperet, cum ante id tempus de suo quisque functus eo munere esset.

54 Pierpaolo Zamorani. Plebi, genti, esercito. Una ipotesi sulla storia di Roma (509-339 a.C.), Milano: Giuffrè, 1987, p. 466.

55 Ibíd., p. 468. 
Liv. 6.14.11-12, en un testimonio del siglo IV con Marco Manlio y con la lucha patricio-plebeya de nuevo en pleno auge, y refiriéndose a los patricios: nec iam possidendis publicis agris contentos esse, nisi pecuniam quoque publicam avertant, ea res si palam fiat, exsolvi plebem aere alieno posse.

Liv. 26.24.11 (210 a. C. $)^{56}$ : alia omnis praeda populi romani essent.

Liv. 26.47.2 (209 a. C.) $)^{57}$ : eos publicos fore populi Romani edixit.

Liv. 30.14.9 ${ }^{[58]}$ : quicquid denique Syphacis fuit praeda populi Romani est.

Plauto ${ }^{59}$, Pers. 507-510, del año 196 o 191, dice: Ea conportatur praeda, ut fiat auctio publicitus.

Liv. 38.23.10 $0^{[60]}$ : ceteram praedam conferre omnes iussit, et aut uendidit, quod eius in publicum redigendum erat, aut cum cura, ut quam aequissima esset, per milites dinisit.

Nep., Timoth. 1.2: et ducenta talenta praedae in publicum rettulit.

$\mathrm{Si}$ observamos atentamente, las expresiones de Livio, de Plauto y de $\mathrm{Ne}$ pote no dejan lugar a duda sobre la existencia de un patrimonio del "Estado".

El primero resulta interesante por la expresión pecuniam publicam referida al tesoro que, guardado para pagar el rescate a los galos y del cual el Senado puede disponer, es escamoteado de forma disimulada.

Los testimonios segundo, tercero y cuarto enfatizan la idea de propiedad, ya que utilizan el verbo sum con una clara idea relacional para expresar "ser propiedad de", en este caso, populi Romani. Siguiendo una orientación similar, el texto plautino muestra una expresión que, siendo como es escasa (publicitus), dice de forma clara que el botín es para el "Estado".

Quizás no deberíamos utilizar el término "Estado", por cuanto puede ser un poco anacrónico, sino una expresión más aséptica como "comunidad política". Sin embargo, ello no es óbice para interpretar el texto con una clara vertiente iuspublicista en la que la auctio se hace para dicha comunidad y, por tanto, el resultado de la misma se depositaría en el Erario.

Un poco más complejo pueden ser el quinto testimonio, en el que se utiliza la expresión in publicum como lugar al que redigere o referre. En nuestra opinión, la utilización de la preposición in en acusativo, indicando movimiento real o figurado, expresa el lugar en el que revierte o se lleva el botín, en este caso, el Erario. Dicha expresión indica de forma patente la Staatseigentum ${ }^{61}$.

56 Texto que reproduce el acuerdo con los etolios sobre el reparto del botín en la guerra contra Filipo y la toma de Acarnia.

57 Toma de Cartagena.

58 Derrota de Sifax.

59 Es sabido que los textos de Plauto pueden estar impregnados de un fuerte sabor griego. $\mathrm{Al}$ respecto ver J. M. PIQUER, Las pruebas no racionales en Roma. Ab urbe condita basta finales de la República, Madrid, 2010, p. 122, n. 321. Lo curioso, sin embargo, es que en este caso no desentona con el régimen romano, por tanto, podemos pensar que se ajusta bien al derecho romano y no tanto al persa.

60 Guerra contra los galos.

61 Heumann-SeCKel, voz "publicum", p. 477. D. 29.5.25.2. 
Nos quedaría añadir, en última instancia, alguno de los testimonios de Cicerón, cuya literalidad resulta clarificadora para entender el final de la República.

Se trata de un texto de las Verrinas, del año 70 a. C., en el que textualmente se dice ${ }^{62}$ : est peculatus, quod publicum populi Romani signum de praeda bostium captum, positum imperatoris nostri nomine non dubitavit auferre, y de donde se deduce de forma palmaria que el crimen de peculado se cometió por detraer para sí una estatua del pueblo romano obtenida del botín recuperado.

\section{CLAVES PARA ENTENDER EL CONCEPTO DE "TITULARIDAD PÚBLICA" EN EL DISCURSO DE CICERÓN CONTRA LA LEY AGRARIA}

El desarrollo del trabajo hasta este momento nos ha permitido perfilar, desde una óptica iuspublicista, la efectiva titularidad jurídica de la comunidad política romana sobre el conjunto de bienes que, como patrimonio, conforman el botín de guerra.

En el iter expositivo resulta ahora necesario buscar algunas claves para interpretar jurídicamente que un bien como el botín sea patrimonio del pueblo romano en el discurso de Cicerón contra la Ley Agraria de Rulo ${ }^{63}$

El valor del testimonio del arpinate en relación con la cuestión del patrimonio del pueblo romano es fundamental pues se puede ver que, según el espíritu de la ley, a los decemviros se les permitía disponer de los recursos que son propios del pueblo romano para poder obtener financiación, entre ellos, y con las salvedades que veremos, del botín de guerra ${ }^{64}$. De lo que se trataba, en definitiva, era de dinero obtenido de los "activos estatales".

En la disposición se pretendía establecer una comisión de decemviri ${ }^{65}$ investida con el poder de una lex curiata de imperio, con pullularis ${ }^{66} \mathrm{y}$ potestatem praetoriam ${ }^{67}$ para establecer colonias y repartir tierras en Italia ${ }^{68}$.

63 BüCHneR, „Cicero", RE (Sonder Ausdruck aus Paulys Realencyclopädie der Classischen Altertumswissenschaft), pp. 827-1274; Arvid AfZelius, „Das Ackerverteilung des P. Servilius Rullus", en Classica et Medievalia, vol. 3, 1940, pp. 211-235; ENGBERT JAN JONKERS, Social and economic commentary on Cicero's de lege agraria orationes tres, Leiden: Brill, 1963; GRAHAM Sumner, "Pompeius, Cicero and Rullus", TAPhA, vol. 97, 1966, pp. 569-582, Klaus Bringmann, Cicero, Darmstadt: Primus, 2010, pp. 83 ss.; Vito Antonio SiRago, Storia agraria romana, 1-2 Napoli: Sgobbo, 1995-1996

64 Klaus Bringmann. Cicero, p. 85. Esta facultad sobre los recursos del pueblo romano es lo que hace que esta rogatio sea interesante para nuestro trabajo, pues no sólo se refiere al patrimonio romano, sino al botín como parte del mismo.

65

66

67

68

A. Afzelius. Das Ackerverteilung, p. 212.

2.13.31.

Cic. de leg.agr. 2.13.32. A. Afzelius, Das Ackerverteilungsgesetz, p. 218; GraHAm Sumner, Cicero, p. 570.

SiRAGo, Storia, 1, pp. 94 ss., cabría pensar que esta ley tendría una finalidad política que podría insertarse en la segunda fase colonial romana. 
Para conseguirlo se otorgó la facultad, entre otras ${ }^{69}$, de administrar el caudal de dinero con el que adquirir las tierras ${ }^{70}$. Este dinero se obtenía, principalmente, de la venta de las tierras, donadas, heredadas o conquistadas, o de bienes del pueblo romano ${ }^{71}$. También el botín contribuyó a incrementar la recaudación, si no se había depositado en el Erario o repartido entre los soldados el oro coronario o el dinero obtenido con la venta de los bienes que le corresponden al general y que no se hubiesen destinado a la construcción de monumentos ${ }^{72}$.

Dichos textos tratan el proceso de venta por subasta de los bienes del pueblo romano, entre ellos del botín ${ }^{73}$, y que llevarían a cabo los decemviros dado que estos ut qua velint solitudine bona populi Romani possint vendere.

En este marco de disposición de recursos propios del pueblo romano se observa, de un modo más esquemático, cuáles son las diversas vías de financiación que tienen los decemviros:

a. La venta de bienes inmuebles que, al pueblo romano, le generan pingües recursos económicos -vectigalia-, tributos.

b. Por último, lo que se obtiene tanto con el botín de guerra -praeda y manubiae-, sometidos ambos al mismo régimen jurídico ${ }^{74}$, como con la contribución exigida a las ciudades ${ }^{75}$-aurum argentum... ex coronario- que no haya sido ingresado en el Erario, lo tenga quien lo tenga, ni gastado en monumentos. Todo ello debía de declararse y remitirse a los decemviros ${ }^{76}$.

Se deduce de la literalidad de la rogatio que, salvo que el botín vaya a parar al Erario, tanto si se ha repartido entre los soldados como si se ha asignado una parte al general que no ha destinado a los monumentos, debe ser declarado y remitido al Senado. Cicerón ${ }^{77}$, siendo un poco más contundente en su retóri-

69 Sumner, Cicero, p. 571 Cic., de leg. agr. 1.4.10, por la que se les autoriza a imponer tributos.

70 De forma crítica con dicha administración, Cicerón afirma que estos decem serían reges aerari, reyes del tesoro, que eripi etiamlibertatem, privatorum pecunias angeri, publicas exhauriri.

71 Cic., de leg. agr. 2.15 .38 ss. Concretamente se les facultaba para la venta de tierras cuya enajenación había sido prevista en el senadoconsulto del año 81 a. C. y de dominios extra itálicos que habían sido propiedad del pueblo romano en el año 88 o después. Obsérvese el detalle con el que se enumeran las listas en de leg. agr. 1.1.2; Afzelius, Das Ackerverteilungsgesetz, p. 219; SUMner, Cicero, p. 571.

72 Cic., de leg. agr. 1.4.12.

73 Cic., de leg. agr. 2.20.54: neque in boc solum inest contumelia, quae vebementer et insignis est et nova, ut ulla res parta bello nondum legibus datis etiam tum imperatore bellum administrante non modo venerit, verum locata sint.

74 Franco Gnoli. Rogatio Servilia agraria, praeda bellica e la responsabilità penale del generale vittorioso per la praeda bellica, en Atti del II Seminario Giuridico Gardesano, Torino, 1980, pp. 297-309, en especial 299.

75 Marianne Coudry. "Les origines républicaines de l'or coronaire", en M. Coudry y M Humm (eds.), Praeda. Butin de guerre et société dans la Rome républicaine / Kriegsbeute und Gesellschaft im republikanischen Rom, Stuttgart, 2009, pp. 153-185, en especial 153. GNOLI, Rogatio, p. 299.

76 Cic., deleg. agr. 2.59.10. GNOLI, Rogatio, p. 300

77 Cic., de leg. 2.54.20. 
ca, afirma en 2.54.20 que todos los bienes que se hayan adquirido durante la guerra podrán ser vendidos o cedidos en arrendamiento, bienes que incluyen tanto los muebles como los inmuebles.

El discurso evidentemente muestra que la ley se debería llevar a cabo mediante los ingresos obtenidos con un bien que pertenece al pueblo, sea directamente, sea mediante su venta.

Queda bastante claro que, en ese contexto de búsqueda de financiación, se recurre a los activos públicos, de los cuales forma parte el botín, como una vía con que obtenerlos, por lo que podemos afirmar que el botín forma parte del patrimonio del populus.

No obstante, el discurso de Cicerón es aún más rico de lo que a simple vista parece, pues se pueden entresacar algunas claves para entender que supone la noción de bien del populus a finales de la República.

La primera clave la encontramos cuando habla de auctionem populi Romani ${ }^{78}$, por tanto, de subasta y susceptible venta de los bienes que el pueblo romano ha adquirido o conquistado, entre otras tierras, en Italia.

Podemos incluso afinar un poco más el pensamiento del arpinate si atendemos a la analogía que hace del proceso de venta por subasta comparándola con el proceder de los pródigos -nequissimi- quienes prefieren que se disponga de su patrimonio in atriis auctionariis ${ }^{79}, \mathrm{y}$, con ello, hablar de la publicidad del proceso de subasta de un patrimonio, asemejando el patrimonio de un pródigo con el patrimonio o bienes del pueblo romano.

Ello demuestra que Cicerón concibe el botín como parte de un patrimonio compuesto por bienes que son publicum $\mathrm{y}$, por tanto, que pertenece al pueblo romano ${ }^{80}$.

¿Cómo podemos entender que pertenece al pueblo romano? Para entenderlo, podemos acudir de nuevo a su discurso contra la Ley Agraria en la que se recogen testimonios referidos a bienes de naturaleza análoga al botín y que expresan claramente qué puede entenderse por "pertenecer".

Así, "pertenecer" puede interpretarse en el sentido de que se ha hecho del pueblo romano -quod certe publicum est populi romani factum-, en este caso, referido a la herencia de Bitinia ${ }^{81}$, cuando utiliza en la rogatio Servilia la expresión a populo Romano abiudicabit ${ }^{82}$ o cuando dice quae vectigalia illis consulibus populo Romano parta sunt ${ }^{83}$. 
El pueblo romano aparece para Cicerón como dueño de unos bienes que patrimonialmente le pertenecen y que forman su aerarium ${ }^{84}$.

Todo lo dicho hasta este momento nos lleva a una conclusión: desde los tiempos de Publícola se concibe el botín como un bien del pueblo, aunque es la evolución política y de sus conceptos la que va afianzando en el lenguaje concepciones más exactas que definan su titularidad.

La segunda clave se refiere al concepto de "Estado" como titular de esos bienes patrimoniales. Cuando Cicerón habla de "Estado" no se refiere a un ente abstracto sino a un conjunto de miembros, un cuerpo cívico, que forman la comunidad política -populus- ${ }^{85}$ y que no sólo tienen la potestad-potestas omnium rerum-operante a través de sus magistrados ${ }^{86}$, sino que también les pertenecen los bienes capturados en las guerras que sostuvieron sus antepasados.

Los testimonios en este sentido son múltiples, no sólo referidos a praeda sino también a otros bienes como los vectigalia ${ }^{87}$ o los que el pueblo de Roma recibe en herencia ${ }^{88}$

Así se observa respecto a la conquista de la ciudad de Mitilene de la que se dice $^{89}$ : quae certe vestrae, Quirites, belli lege ac victoriae iure factae sunt $\mathrm{y}$, con ello, que la ciudad pertenece a los ciudadanos por derecho de guerra y victoria.

Por último, se puede interpretar con Cicerón que el botín capturado al enemigo es un bien del pueblo romano con el que se enriquece ${ }^{90}$.

Ello no sólo se observa en los sucesivos fragmentos de Livio, sino que tiene su continuidad en los testimonios de Cicerón al afirmar en de re publica ${ }^{91}$ : et cum ipse nibil ex praeda domum suam reportaret, locupletare civis non destitit.

Con tal fortuna, no sólo se trata de enriquecer al pueblo, sino que se destina al cumplimiento de los fines del "Estado"92. Tal es el espíritu que se deduce del discurso de Cicerón contra la Ley Agraria, pues el botín, junto con los otros

84 Cic., de leg. agr. 2.4.10. En de leg. agr. 2.6.15 utiliza el término publicas.

85 Cic., de rep. 1.25. 39: 'Est igitur', inquit Africanus, 'res publical res populi, populus autem non omnis bominum coetus quoquo modo congregatus, sed coetus multitudinis iuris consensu et utilitatis communione sociatus'. Al respecto, ORESTANO, Il problema, p. 112, interpreta el fragmento desde la óptica jurídica al decir que res se refiere al "ordenamiento jurídico", en este caso, romano como "trasposizione personalistica" de este fragmento. Respecto a la concepción y formación del Estado romano, nos remitimos a la abundante bibliografía que se ha escrito al respecto y que no es posible tratar de forma pormenorizada en este trabajo que no aspira, en este punto, a adentrarse en la cuestión.

86 Liv. 8.33.17. Orestano, Il problema, p. 213. Para Catalano, Populus, p. 106, se evidencia el aspecto de la unión y de la pluralidad. Textualmente se refiere a la expresión populus Romanus Quirites como "concezione complessa che tiene conto dell'unione, della riunione e della pluralità".

87 Cic., deleg. agr. 2.17.47.

88 Cic., deleg. agr. 2.15.40, como es el caso de Bitinia.

89 Cic., de leg. agr. 2.16.40. JONKERS, Social, p. 40.

90 Así, Fernández de Buján, Derecho público, p. 251.

91 Cic., de rep. 2.9.15

92 Cic., de leg.agr. 1.2.4. JonKERS, Social, p. 15. 
recursos del "Estado", se pone a disposición de los decemviros para que, con él, lleven a efecto el cumplimiento de la norma y que, en este caso, supondría un empobrecimiento del pueblo.

Se podría decir que a finales de la República, al menos para Cicerón, el botín de guerra aparece como un bien que pertenece a cada uno de los ciudadanos que forman el populus y que, en cuanto que es un bien patrimonial, es una parte de la riqueza del mismo. El patrimonio del populus es su riqueza.

\section{CONSIDERACIONES FINALES}

El botín de guerra del que hemos hablado, o sea la praeda bellica, constituye el producto obtenido por la acción comunitaria y se compone, como es obvio, por una parte de los bienes que la comunidad política captura al enemigo. Decimos que es una parte porque, en la cultura social y jurídica romana, el resto de bienes tienen una naturaleza propia que los diferencia entre sí, como son las manubiae o los spolia.

Es evidente que la guerra, como acción comunitaria, en caso de victoria, provee de esos bienes que son tan necesarios, no sólo para los individuos, especialmente de los soldados cuando pueden obtener un beneficio directo de los mismos que de otro modo no tendrían, sino también para la comunidad. Por tanto, surge la cuestión acerca de quién es el "titular" de dichos bienes.

A lo largo del trabajo hemos pretendido profundizar en esta cuestión durante el período republicano e intentar adentrarnos en la concepción que la comunidad romana podía tener sobre la praeda a través de las fuentes literarias que son, en definitiva, las que más y mejores datos nos ofrecen para poder interpretar dicha realidad.

Su estudio nos ha permitido ver que la mejor forma de enfocar esta realidad es la iuspublicista, ya que se puede apreciar desde principios de la República un paradigma claro: que la disposición del botín corresponde a unos órganos públicos que no son titulares del mismo.

El problema pues no lo encontramos sólo en conceptualizar que un bien se pudiese concebir como bien del pueblo, sino también en ver cómo se conforma a lo largo de la República, especialmente si vemos que en las primeras décadas o siglos los soldados plebeyos mostraron una especial avidez por obtener el botín con el que poder solventar sus apuros económicos.

Nuestro estudio nos ha llevado a concluir que la toma de Veyes a principios del siglo IV a. C. supuso un cambio en la concepción del botín como bien del pueblo romano, no tanto porque no se concibiese como tal en épocas anteriores, sino porque la realidad sobre la que se sustentará en los siglos venideros cambia como consecuencia de la inicial superación de los conflictos patricio-plebeyos y, con ello, de un cambio en la concepción política del populus. Esto supuso una modificación de la conceptualización del botín al hacerlo como bien que 
está in potestatem populi Romani, y por tanto, un modo más preciso de expresar e interpretar jurídicamente la realidad acorde con una nueva realidad política.

A partir de ese momento la concepción patrimonial del botín se hace más patente como bien que corresponde al pueblo $\mathrm{y}$, con ello, a cada uno de los ciudadanos: bienes que, en definitiva, son una parte de su riqueza. Al menos, así se entiende y perfila en tiempos de Cicerón.

Queda pues claro que, siendo la praeda propiedad del pueblo romano, la disponibilidad se mueve entre dos polos, como son el del general y el del Senado, teniendo mayor incidencia la realidad sociopolítica del momento. Es por ello que, a lo largo de las noticas que hemos obtenido, se detectan situaciones de insatisfacción como consecuencia de las injusticias o prevalencias de intereses políticos.

\section{BIBLIOGRAFÍA}

AnKum, Hans. "La noción de ius publicum en derecho romano", Anuario de bistoria del derecho español, vol. 53, 1983.

Bona, Ferdiando. "Osservazioni sull'acquisto delle 'res hostium' a seguito di 'direptio"', en Studia et documenta bistoriae iuris, vol. 24, 1958.

Bona, Ferdinando. "Praeda di guerra e occupazione privata di 'res hostium'", en Studia et documenta bistoriae iuris, vol. 25, 1959.

Catalano, Pierangelo. Populus Romanus Quirites, Torino: Giappichelli,1975.

Coudry, Marianne. "Partage et gestion du butin dans la Rome républicaine: procédures et enjeux", en Praeda, Butin de guerre et société dans la Rome républicaine, dirs. Marianne Coudry y Michel Humm, Stuttgart: Steiner 2009.

De Martino, Francesco. "La costituzione della città-stato", en Storia di Roma. Roma in Italia, dirs. Arnaldo Momigliano y Aldo Schiavone, Torino: Einaudi, 1988.

DuméZIL Georges. La religión romaine archaïque, Paris: Payot, 1966.

FABBRINI, FABRIZIO. La definizione del potere in Roma antica, Roma: Euroma La Goliardica, 1983.

Fernández de BujÁn, Antonio. Derecho público romano, Madrid, 19. a ed., 2016.

Guarino, Antonio. La rivoluzione della plebe, Napoli: Liguori, 1975.

JONKERS, JAN. Social and economic commentary on Cicero's de lege agraria orationes tres, Leiden: Brill, 1963.

KASER, MAX. "Ius publicum und ius privatum", en Zeitscbrift Savigny Stitfung, vol. 103, 1986. 
Nicolet, Claude. Le métier de citoyen dans la Rome républicaine, Paris: Biblioteque des histoires, 1976.

Orestano, Riccardo. Il problema delle persone giuridiche in diritto romano, Torino: Giappichelli 1968.

Ortu, Rosanna. "La guerra tra economia e diritto nella antica Roma", en Diritto@ Storia, vol. 4, 2005.

Robleda, Olis. "La capacidad jurídica del populus romanus", en St. Grosso 3, Torino: Giappichelli, 1968.

Sirago, Vito Antonio. Storia agraria romana, Napoli: Sgobbo, t. 1-2, 1995-1996.

Suerbaum, Werner. Von antiken zum frümittelalterlichen Staatbegriff, Münster: Aschendorffsche Verlagsbuchhandlung, 1961.

Tondo, Salvatore. "Sacramentum militiae nell'ambiente culturale romano", en Studia et documenta bistoriae iuris, vol. 29, 1967.

Vogel, Karl-Heinz. "Zur rechtlichen Behandlung der römischen Kriegsgewinne", en Zeitschrift Savigny Stiftung, vol. 66, 1948.

Wissowa, GeORGE. Religion und Kultus der Römer, München: Beck, 1971.

Zamorani, Pierpaolo. Plebi, genti, esercito. Una ipotesi sulla storia di Roma (509-339 a.C.), Milano: Giuffrè, 1987. 